\title{
Review: Do We Still Need a Viability Study before Considering Revascularization in Patient with Stable Coronary Artery Disease and Significant Left Ventricular Systolic Dysfunction?
}

\author{
Hanan Albackr, Abdulelah F. Al Mobeirek, Mostafa Al Shamiri, Turki B. Albacker \\ King Fahad Cardiac Center, College of Medicine, King Saud University, Riyadh, KSA \\ Email: ${ }^{*}$ talbacker@ksu.edu.sa
}

Received 12 February 2014; revised 1 March 2014; accepted 20 March 2014

Copyright @ 2014 by authors and Scientific Research Publishing Inc.

This work is licensed under the Creative Commons Attribution International License (CC BY).

http://creativecommons.org/licenses/by/4.0/

c) (i) Open Access

\begin{abstract}
Patients with ischemic cardiomyopathy constitute a heterogeneous group of patients with an extremely complex condition in which many factors play an important prognostic role. So it is difficult and probably unrealistic to expect that a single feature like presence of viable myocardium would provide an unequivocal answer to a critical question of revasculrization or not for all patients. Opposite to the hopes of investigators and physicians involved in the care of these patients, the findings of prospective studies with the use of different viability testing methods did not help in the decision-making process regarding CABG in ischemic cardiomyopathy. Instead, they left us with the same dilemma. The implication of most of these trials is that in patients with CAD and significant $\mathrm{LV}$ dysfunction, assessment of myocardial viability does not identify patients who will have the greatest survival benefit from adding CABG to aggressive medical therapy. In the clinical practice, these observations remind physicians to consider the multiplicity of factors involved in the decision-making process for patients with such a complex disease.
\end{abstract}

\section{Keywords}

Viability; Revascularization; Coronary Artery Bypass Grafting; Left Ventricular Dysfunction

\footnotetext{
Corresponding author.

How to cite this paper: Albackr, H., Al Mobeirek, A.F., Al Shamiri, M. and Albacker, T.B. (2014) Review: Do We Still Need a Viability Study before Considering Revascularization in Patient with Stable Coronary Artery Disease and Significant Left Ventricular Systolic Dysfunction? International Journal of Clinical Medicine, 5, 242-248. http://dx.doi.org/10.4236/ijcm.2014.55038
} 


\section{Introduction}

Chronic heart failure is becoming the main clinical challenge in cardiology in terms of the number of patients involved. Recent estimations have shown that 5 million patients in the United States have chronic heart failure, with 550,000 new patients being diagnosed annually, resulting in over 1 million hospitalizations [1]. The most important cause of heart failure is chronic coronary artery disease. Gheorghiade and Bonow [2] pooled data from 13 randomized multicenter heart failure drug trials (involving over 20,000 patients) reported between 1986 and 1997. They found that coronary artery disease was the underlying etiology in almost $70 \%$ of the patients.

Revascularization is associated with increased risk in patients with a severely depressed LV ejection fraction (LVEF) [3]. Moreover, not all patients with ischemic cardiomyopathy show improvement in contractile function after revascularization; approximately one third of dysfunctional segments improve in function, and approximately $40 \%$ of patients show improvement in the LVEF [4]. Therefore, in view of the high morbidity and mortality associated with revascularization procedures, careful selection of patients who may benefit from revascularization procedures appears to be warranted.

LV dysfunction in patients with CAD is not always an irreversible process, as LV function may improve substantially after CABG. Over the last 2 decades, evidence has been collected that patients with dysfunctional but viable myocardium are likely to benefit from revascularization, whereas patients without viable myocardium will not benefit. Assessment of myocardial viability is often used to predict improvement in LV function after CABG and thus select patients for CABG. Numerous studies have suggested that identification of viable myocardium also predicts improved survival after CABG.

\section{Definition of Myocardial Viability}

The concept of myocardial hibernation was used to describe a condition of chronic sustained abnormal contraction attributable to chronic underperfusion in patients who have coronary artery disease and in whom revascularization causes the recovery of LV function [5]. Myocardial stunning has been defined as reversible myocardial contractile dysfunction in the presence of normal resting myocardial blood flow [6] [7]. Myocardial hibernation and myocardial stunning are pathophysiologic entities that may coexist in patients with ischemic cardiomyopathy. Repeated ischemic attacks may induce chronic dysfunction in the presence of normal or mildly reduced resting perfusion; this condition was referred to as repetitive stunning. It appears that there is a temporal progression from stunning, characterized by (nearly) normal flow (with reduced flow reserve), to hibernation, with reduced resting flow.

Several noninvasive techniques have been developed to detect signs of viability, such as an intact cell membrane, residual glucose metabolism, or preserved contractility in response to dobutamine stimulation. Hibernating myocardium represents a delicate balance among flow, function, and viability and because myocytes adapt their activity level to prevailing circumstances, it is likely that some characteristics (e.g., contractile reserve) are lost while more basal characteristics, such as glucose metabolism and cell membrane integrity, are preserved [8].

\section{Endpoints in Viability Studies}

Currently available studies evaluating the role of noninvasive imaging techniques in the assessment of myocardial viability have focused on various clinical endpoints. The endpoints used in viability studies after revascularization include improvement in regional LV function (segments), improvement in global LV function (LVEF), improvement in symptoms (New York Heart Association [NYHA] functional class), improvement in exercise capacity (metabolic equivalents), reverse LV remodeling (LV volumes), prevention of sudden death (ventricular arrhythmias), and long term prognosis (survival). Improvement in function after revascularization is still considered the final proof of viability.

In a recent analysis of pooled data, including 105 studies (with 3003 patients) that focused on viability assessment (with nuclear imaging and dobutamine stress echocardiography), 15,045 dysfunctional segments were analyzed for viability with noninvasive testing; 7941 segments (53\%) showed improvement in function after revascularization [9]. Of these 7941 segments with improvement in function, 84\% were considered to be viable according to the imaging modalities.

From a clinical point of view, improvement in global LV function (LVEF) may be more important than im- 
provement in regional function. The LVEF has been demonstrated to be a very powerful predictor of prognosis. The precise proportions of viable segments needed to result in improvement in the LVEF differed among the studies (Table 1), and it is currently unclear how much viability is needed to result in improvement in the LVEF after revascularization. The available evidence suggests that $20 \%-30 \%$ of the left ventricle needs to be viable to allow improvement in the LVEF.

Besides improvement in the LVEF, improvement in symptoms and exercise capacity may be clinically relevant, although few data are available on these topics. Published studies showed that the mean NYHA class improved significantly in patients with viable myocardium [10]-[12]. Individual data, however, varied significantly, and accurate prediction of improvement in symptoms for an individual patient remains difficult.

Another potential endpoint in viability assessment is the prediction of LV remodeling. LV volumes are powerful predictive parameters. Small studies have described the relationship between viability and LV remodeling. Mule et al. [13] reported that patients with residual viability or ischemia (involving $20 \%$ of the left ventricle) demonstrated reverse remodeling after revascularization, with a significant reduction in both LV end-systolic and end-diastolic volumes after revascularization. It also showed that patients with predominantly scar tissue exhibited ongoing adverse LV remodeling, with an increase in both LV end-systolic and end-diastolic volumes. Therefore, surgery for patients with scar tissue did not result in reverse LV remodeling.

The final, most important, endpoint is long-term prognosis. A substantial number of studies has evaluated the prognostic value of viability in relation to therapy. These studies consistently showed a low event rate in patients who had viable myocardium and who underwent revascularization. In line with this finding, Rohatgi et al. [14] demonstrated that revascularization in patients with a substantial amount of viable myocardium reduces the number of hospital readmissions for congestive heart failure.

Table 1. End points of major viability trials.

\begin{tabular}{|c|c|c|c|c|c|}
\hline Author & Year & $\begin{array}{c}\text { No. of } \\
\text { patients }\end{array}$ & Design & Test used & Main outcome \\
\hline Almohmmed A [26] & Heart 1998 & 27 & Observational & PET & $\begin{array}{l}52 \% \text { of viability suitable } \\
\text { for revascularization }\end{array}$ \\
\hline Auerbach MA [27] & $\begin{array}{c}\text { Circulation } \\
1999\end{array}$ & 283 & Observational & PET & $\begin{array}{l}55 \% \text { of viability, } 27 \% \\
\text { improved with revasculrization }\end{array}$ \\
\hline Schinkel AFL [28] & Heart 2002 & 104 & $\begin{array}{l}\text { A retrospective } \\
\text { observational study }\end{array}$ & SPECT & $\begin{array}{l}61 \% \text { of viability improved } \\
\text { with revasculrization }\end{array}$ \\
\hline Schinkel AFL [29] & Am J Cardiol 2001 & 150 & Observational & DSE & $\begin{array}{l}37 \% \text { of viability improved } \\
\text { with revasculrization }\end{array}$ \\
\hline Bonow RO [17] & $\begin{array}{l}\text { N Engl J Med } \\
2011 \text { (Stich) }\end{array}$ & 601 & $\begin{array}{l}\text { Randomized } \\
\text { controlled } \\
\text { trial }\end{array}$ & DSE and SPECT & $\begin{array}{l}\text { No significant interaction between } \\
\text { viability status and treatment } \\
\text { assignment with respect to mortality }\end{array}$ \\
\hline Beanlands RS [23] & $\begin{array}{c}\text { Am J Cardiol } \\
2007 \text { (PARR-2) }\end{array}$ & 218 & $\begin{array}{l}\text { Randomized } \\
\text { controlled trial }\end{array}$ & PET & $\begin{array}{l}\text { Did not demonstrate a significant } \\
\text { reduction in cardiac events in } \\
\text { patients with LV dysfunction and } \\
\text { coronary disease for FDG } \\
\text { PET-assisted management versus } \\
\text { standard care }\end{array}$ \\
\hline Cleland JGF [25] & $\begin{array}{l}\text { Eur J Heart Fail } \\
2011 \text { (HEART) }\end{array}$ & 138 & $\begin{array}{l}\text { Unblinded randomized } \\
\text { controlled }\end{array}$ & $\begin{array}{c}\text { DSE and } \\
\text { NUCLEAR }\end{array}$ & $\begin{array}{l}\text { There were no differences in } \\
\text { mortality by intention-to-treat with } \\
\text { use of viability testing }\end{array}$ \\
\hline Stipac AV [30] & Heart 2013 & 115 & $\begin{array}{l}\text { Prospective observational } \\
\text { cohort study. }\end{array}$ & DSE & $\begin{array}{l}\text { It appears that patients with LV } \\
\text { dysfunction, but without viable } \\
\text { myocardium, may also benefit from } \\
\text { myocardial revascularisation. }\end{array}$ \\
\hline Shah DJ [31] & JAMA 2013 & 1055 & Observational prospective & MRI & $\begin{array}{l}\text { Among patients with CAD referred } \\
\text { for CMR and found to have regional } \\
\text { wall thinning, limited scar burden } \\
\text { was present in } 18 \% \text { and was } \\
\text { associated with improved } \\
\text { contractility and resolution of wall } \\
\text { thinning after revascularization }\end{array}$ \\
\hline
\end{tabular}




\section{Is Viability Imaging Still Relevant?}

Allman et al. [15] performed a meta-analysis of 24 prognostic studies (with 3088 patients) that used various viability techniques and that showed a 3.2\% annual death rate in patients who had viable myocardium and who underwent revascularization, compared with a $16 \%$ annual death rate in patients who had viable myocardium and who were treated medically.

Although Prior observational studies and meta-analyses [16] had suggested that those with viability demonstrated on noninvasive testing fared better with revascularization than medical therapy alone, however most of these studies were based on retrospective or cohort analyses, in addition most of the cohort studies carried out before modern aggressive medical therapy.

The concepts of myocardial viability and viability testing are logical and mechanistically sound [17]. Reasonable, though non-definitive, evidence from over 100 nonrandomized studies of more than 3000 patients with viability testing in the last 2 decades has consistently demonstrated its usefulness [18]-[20]. Based on These observational findings, viability testing was considered as a class IIa recommendation in the American College of Cardiology/American Heart Association practice guidelines [21] and support the use of viability testing in moderate-to-severe ischemic LV systolic dysfunction.

The lack of randomized controlled trials (RCT) of viability testing was addressed partly by the PARR-2 trial, the largest to date, RCT of PET viability testing [22]. PARR-2 stratified patients with severe LV systolic dysfunction (presumed ischemic) to recent angiography or not, then randomized to PET-guided management ( $\mathrm{n}=$ 218) versus standard care without PET (where an alternative test could be considered [n $=212]$ ). At 1 year, PARR-2 demonstrated no significant difference in the composite primary outcome of cardiac death, myocardial infarction (MI), or recurrent hospitalization between the 2 arms. Although well-conducted, PARR-2 had lower adherence to PET-guided recommendations, which may have reduced the ability to detect a difference in the primary outcome. When only patients adhering to PET-guided recommendations were included, the PET adherence group had significantly better outcome than the standard care group did. Furthermore, 39\% of patients in the PET arm and about two-thirds of patients in the standard arm had at least one other form of functional testing within3 months before or after randomization, which may have introduced a significant crossover effect and bias against PET. Thus, whereas randomization in PARR-2 was designed to reduce selection and referral biases, the high non-adherence rate and significant use of other testing in the standard arm highlight the remarkable challenges of this type of trial design.

The HEART (Heart Failure Revascularization Trial) was an unblinded clinical study that aimed to randomize 800 patients with symptomatic HF, LV ejection fraction < 35\%, and evidence of substantial myocardial viability to either conservative management or coronary angiography with the intention of revascularization [23]. Unfortunately, the study was stopped early due to problems with recruiting and funding. Of the 138 patients enrolled, 69 were randomized to a strategy of revascularization, but only 45 ultimately underwent a procedure. There were no differences in mortality by intention-to-treat, suggesting a lack of benefit of revascularization therapy in patients with viability. However, the trial was clearly underpowered to address this endpoint.

With the publication of the stich trial (Surgical Treatment for Ischemic Heart Failure) trial [24] and the viability substudy [25], questions have arisen regarding the utility of viability testing in patients with left ventricular systolic dysfunction and coronary artery disease (CAD) prior to revascularization decisions. Stich [24] was the first prospective randomized trial testing the hypothesis that CABG improves survival in patients with ischemic LV dysfunction compared to outcome with aggressive medical therapy. It also Provides the first opportunity to assess the interaction between myocardial viability and survival in randomized patients who were all eligible for medical management alone and eligible for CABG. Stich demonstrated a significant association between myocardial viability and outcome, but this association is rendered non-significant when subjected to a multivariable analysis that includes other prognostic variables.

Stich has failed to demonstrate a significant interaction between myocardial viability and medical versus surgical treatment with respect to mortality. So it concluded that in patients with CAD and LV dysfunction, assessment of myocardial viability does not identify patients who will have the greatest survival benefit from adding CABG to aggressive medical therapy.

In addition to overall trial limitations (Table 2), the STICH viability substudy, did not mandate viability testing or randomize according to viability testing results. Rather, viability testing was performed at the clinician's discretion in about one-half of eligible patients. Thus, whereas the substudy has the major strength of being part 
1) Lack of viability data on all patients; patients represent a subpopulation of STICH

2) Analysis limited to SPECT and DE, not PET or cardiac MRI

3) Fundamental differences in viability information provided by SPECT and DE, and differences in analytic methods between the two methods

4) Revascularization was not guided by the presence of viability

5) Optional viability testing was done upon clinical decision

6) Acceptable viability tests do not have high sensitivity or negative predictive value for identifying patients with viable myocardium

of a rigorously conducted RCT, the results should be interpreted cautiously given these limitations. Furthermore, although the viability tests accepted in STICH are commonly used in practice, these approaches have lower sensitivity and negative predictive value than PET or contrast-enhanced cardiac magnetic resonance [24].

Recently in hearts there is a Prospective observational cohort study [30] that was conducted on 115 consecutive patients to assess the effect of surgical revascularisation on left ventricular (LV) systolic function in patients with viable and non-viable dysfunctional LV segments determined by low dose dobutamine stress echocardiography (DSE). They found that it appears that patients with LV dysfunction, but without viable myocardium, may also benefit from myocardial revascularization. Functional recovery continuously occurs throughout the first year after surgical treatment.

Also Shah and his colleagues [31] looked at regional left ventricular (LV) wall thinning that was believed to represent chronic transmural myocardial infarction and scar tissue and the effect of that on myocardial viability after revascularization.

They found that among patients with CAD referred for CMR and found to have regional wall thinning, limited scar burden was present in $18 \%$ and was associated with improved contractility and resolution of wall thinning after revascularization. These findings are not consistent with common assumptions.

\section{Implication}

So far none of the prospective trials that addressed the viability question supports the use of viability testing as a helpful or useful test in the decision-making process regarding revascularization in patients with ischemic cardiomyopathy. This contradicts the well known biological theory that improvement in systolic function with revascularization (only possible in viable segments) is associated with better prognosis. Hence, clinicians are now presented with the dilemma of plausible biological concepts already incorporated into practice with the opposing findings of recent clinical trials.

There are a number of possible explanations for these discrepancies. First, limitations in study design and completion may have prevented the detection of a true interaction between viability status and the benefit of revascularization. Second, it is possible that the advances in medical and device therapy have markedly reduced the added benefit of revascularization, such that it is difficult to demonstrate further improvement in clinical outcomes. Third, the benefit of CABG may not be related to revascularization of viable segments but rather to revascularization of potentially ischemic segments.

Furthermore patients with ischemic cardiomyopathy constitute a heterogeneous population with an extremely complex condition in which multiple factors play an important prognostic role. So, it would be simplistic to expect that a single feature like the presence of viable myocardium would provide the answer to such a critical question for all patients.

\section{Conclusion}

Contrary to the hopes of investigators and physicians involved in the care of these patients, the findings of prospective studies have not simplified the decision-making process regarding CABG in ischemic cardiomyopathy. Instead, they are valuable in that they demystify the emphasis previously placed-without appropriate evidence-the significance of myocardial viability, so controversy still exists in the management of such a complex multifactorial disease. Clearly, there is room for further investigation in this arena to definitively answer this important question in clinical cardiovascular medicine.

\section{References}

[1] American Heart Association (2006) Heart Disease and Stroke Statistics. American Heart Association. 
[2] Gheorghiade, M. and Bonow, R.O. (1998) Chronic Heart Failure in the United States: A Manifestation of Coronary Artery Disease. Circulation, 97, 282-289. http://dx.doi.org/10.1161/01.CIR.97.3.282

[3] Levy, D., Kenchaiah, S., Larson, M.G., et al. (2002) Long-Term Trends in the Incidence of and Survival with Heart Failure. New England Journal of Medicine, 347, 1397-1402. http://dx.doi.org/10.1056/NEJMoa020265

[4] Schinkel, A.F.L., Poldermans, D., Vanoverschelde, J.L.J., et al. (2004) Incidence of Recovery of Contractile Function Following Revascularization in Patients with Ischemic Left Ventricular Dysfunction. American Journal of Cardiology, 93, 14-17. http://dx.doi.org/10.1016/j.amjcard.2003.09.005

[5] Rahimtoola, S.H. (19890 The Hibernating Myocardium. American Heart Journal, 117, 211-221. http://dx.doi.org/10.1016/0002-8703(89)90685-6

[6] Heyndrickx, G.R., Millard, R.W., McRitchie, R.J., Maroko, P.R. and Vatner, F. (1975) Regional Myocardial Functional and Electrophysiological Alterations after Brief Coronary Artery Occlusion in Conscious Dogs. Journal of Clinical Investigation, 56, 978-985. http://dx.doi.org/10.1172/JCI108178

[7] Braunwald, E. and Kloner, R.A. (1982) The Stunned Myocardium: Prolonged, Postischemic Ventricular Dysfunction. Circulation, 66, 1146-1149. http://dx.doi.org/10.1161/01.CIR.66.6.1146

[8] Bonow, R.O. (1999) Contractile Reserve and Coronary Blood Flow Reserve in Collateral Dependent Myocardium. Journal of the American College of Cardiology, 33, 705-707.

[9] Bax, J.J., Poldermans, D., Elhendy, A., Boersma, E. and Rahimtoola, S.H. (2001) Sensitivity, Specificity, and Predictive Accuracies of Various Noninvasive Techniques for Detecting Hibernating Myocardium. Current Problems in Cardiology, 26, 142-186. http://dx.doi.org/10.1067/mcd.2001.109973

[10] DiCarli, M.F., Asgarzadie, F., Schelbert, H.R., et al. (1995) Quantitative Relation between Myocardial Viability and Improvement in Heart Failure Symptoms after Revascularization in Patients with Ischemic Cardiomyopathy. Circulation, 92, 3436-3444. http://dx.doi.org/10.1161/01.CIR.92.12.3436

[11] Bax, J.J., Visser, F.C., Poldermans, D., et al. (2001) Relationship between Preoperative Viability and Postoperative Improvement in LVEF and Heart Failure Symptoms. Journal of Nuclear Medicine, 42, 79-86.

[12] Marwick, T.H., Zuchowski, C., Lauer, M.S., Secknus, M.A., Williams, M.J. and Lytle, B.W. (1999) Functional Status and Quality of Life in Patients with Heart Failure Undergoing Coronary Bypass Surgery after Assessment of Myocardial Viability. Journal of the American College of Cardiology, 33, 750-758. http://dx.doi.org/10.1016/S0735-1097(98)00642-1

[13] Mule, J., Bax, J.J., Zingone, B., et al. (2002) The Beneficial Effect of Revascularization on Jeopardized Myocardium: Reverse Remodeling and Improved Long-Term Prognosis. European Journal Cardio-Thoracic Surgery, 22, 426-430. http://dx.doi.org/10.1016/S1010-7940(02)00359-7

[14] Rohatgi, R., Epstein, S., Henriquez, J., et al. (2001) Utility of Positron Emission Tomography in Predicting Cardiac Events and Survival in Patients with Coronary Artery Disease and Severe Left Ventricular Dysfunction. American Journal of Cardiology, 87, 1096-1099. http://dx.doi.org/10.1016/S0002-9149(01)01468-0

[15] Allman, K.C., Shaw, L.J., Hachamovitch, R. and Udelson, J.E. (2002) Myocardial Viability Testing and Impact of Revascularization on Prognosis in Patients with Coronary Artery Disease and Left Ventricular Dysfunction: A MetaAnalysis. Journal of the American College of Cardiology, 39, 1151-1158. http://dx.doi.org/10.1016/S0735-1097(02)01726-6

[16] Allman, K.C., Shaw, L.J., Hachamovitch, R. and Udelson, J.E. (2002) Myocardial Viability Testing and Impact of Revascularization on Prognosis in Patients with Coronary Artery Disease and Left Ventricular Dysfunction: A Metaanalysis. Journal of the American College of Cardiology, 39, 1151-1158. http://dx.doi.org/10.1016/S0735-1097(02)01726-6

[17] Chareonthaitawee, P., Gersh, B.J., Araoz, P.A. and Gibbons, R.J. (2005) Revascularization in Severe Left Ventricular Dysfunction: the Role of Viability Testing. Journal of the American College of Cardiology, 46, 567-574. http://dx.doi.org/10.1016/j.jacc.2005.03.072

[18] Schinkel, A.F., Bax, J.J., Poldermans, D., Elhendy, A., Ferrari, R. and Rahimtoola, S.H. (2007) Hibernating Myocardium: Diagnosis and Patient Outcomes. Current Problems in Cardiology, 32, 375-410. http://dx.doi.org/10.1016/j.cpcardiol.2007.04.001

[19] Camici, P.G., Prasad, S.K. and Rimoldi, O.E. (2008) Stunning, Hibernation, and Assessment of Myocardialviability. Circulation, 117, 103-114. http://dx.doi.org/10.1016/j.cpcardiol.2007.04.001

[20] Hillis, L.D., Smith, P.K., Anderson, J.L., et al. (2011) 2011 ACCF/AHA Guideline for Coronary Artery Bypass Graft Surgery: A Report of the American College of Cardiology Foundation/American Heart Association Task Force on Practice Guidelines. Journal of the American College of Cardiology, 58, e123-e210. http://dx.doi.org/10.1016/j.jacc.2011.08.009

[21] Beanlands, R.S., Nichol, G., Huszti, E., et al., for the PARR-2 Investigators (2007) F-18-Fluorodeoxyglucose Positron 
Emission Tomography Imagingassisted Management of Patients with Severe Left Ventricular Dysfunction and Suspected Coronary Disease: A Randomized, Controlled Trial (PARR-2). Journal of the American College of Cardiology, 50, 2002-2012. http://dx.doi.org/10.1016/j.jacc.2007.09.006

[22] Cleland, J.G.F., Calvert, M., Freemantle, N., et al. (2011) The Heart Failure Revascularisation Trial (HEART). European Journal of Heart Failure, 13, 227-233. http://dx.doi.org/10.1093/eurjhf/hfq230

[23] Velazquez, E.J., Lee, K.L., Deja, M.A., et al., for the STICH Investigators (2011) Coronary-Artery Bypass Surgery in Patients with Left Ventricular Dysfunction. The New England Journal of Medicine, 364, 1607-1616. http://dx.doi.org/10.1056/NEJMoa1100356

[24] Bonow, R.O., Maurer, G., Lee, K.L., et al., for the STICH Investigators (2011) Myocardial Viability and Survival in Ischemic Left Ventricular Dysfunction. The New England Journal of Medicine, 364, 1617-1625. http://dx.doi.org/10.1056/NEJMoa1100358

[25] Schinkel, A.F., Bax, J.J., Poldermans, D., Elhendy, A., Ferrari, R. and Rahimtoola, S.H. (2007) Hibernating Myocardium: Diagnosis and Patient Outcomes. Current Problems in Cardiology, 32, 375-410. http://dx.doi.org/10.1016/j.cpcardiol.2007.04.001

[26] Al-Mohammad, A., Mahy, I.R., Norton, M.Y., et al. (1998) Prevalence of Hibernating Myocardium in Patients with Severely Impaired Ischaemic Left Ventricles. Heart, 80, 559-564.

[27] Auerbach, M.A., Schöder, H., Gambhir, S.S., et al. (1999) Prevalence of Myocardial Viability as Detected by Positron Emission Tomography in Patients with Ischemic Cardiomyopathy. Circulation, 99, 2921-2926. http://dx.doi.org/10.1161/01.CIR.99.22.2921

[28] Schinkel, A.F.L., Bax, J.J., Sozzi, F.B., et al. (2002) Prevalence of Myocardial Viability Assessed by Single Photon Emission Computed Tomography in Patients with Chronic Ischaemic Left Ventricular Dysfunction. Heart, 88, 125-130. http://dx.doi.org/10.1136/heart.88.2.125

[29] Schinkel, A.F.L., Bax, J.J., Boersma, E., Elhendy, A., Roelandt, J.R.T.C. and Poldermans, D. (2001) How Many Patients with Ischemic Cardiomyopathy Exhibit Viable Myocardium? American Journal of Cardiology, 88, 561-564. http://dx.doi.org/10.1016/S0002-9149(01)01741-6

[30] Stipac, A.V., Stankovic, I., Vidakovic, R., Putnikovic, B., Ilic, I., Milicic, B. and Neskovic, A.N. (2013) Effect of Myocardial Revascularisation on Left Ventricular Systolic Function in Patients with and without Viable Myocardium: Should Non-Viable Segments Be Revascularised? Heart, 99, 1749-1754. http://dx.doi.org/10.1136/heartjnl-2013-304288

[31] Shah, D.J., Kim, H.W., James, O., Parker, M., Wu, E., Bonow, R.O., Judd, R.M. and Kim, R.J. (2013) Prevalence of Regional Myocardial Thinning and Relationship with Myocardial Scarring in Patients with Coronary Artery Disease. JAMA, 309, 909-918. http://dx.doi.org/10.1001/jama.2013.1381 